\title{
The role of elements of the Economics of Quality in mathematical modelling of socio- economic processes
}

\author{
Vladimir Okrepilov ${ }^{1, *}$, Natalia Chetyrkina ${ }^{2}$, and Mikhail Krylov ${ }^{3}$ \\ ${ }^{1}$ Institute for Regional Economic Studies Russian Academy of Sciences, St. Petersburg, Russian \\ Federation \\ ${ }^{2}$ Staint Petersburg State University of Economics, St. Petersburg, Russian Federation \\ ${ }^{3}$ North-West Institute of Management of the Russian Presidential Academy of National Economy and \\ Public Administration, St. Petersburg, Russian Federation
}

\begin{abstract}
Nowadays, when making managerial decisions, specialists are faced with the need to process ever-increasing volumes of information in an increasingly shorter time. The need for the development of a methodology for social forecasting on the basis of detailed development models is growing. Since the basis of the activity of the socio-economic system of any level is an anthropogenic factor, this increases the degree of probability of the implementation of various scenarios. To develop more accurate forecasts, it is necessary to use the tools of the economics of quality - standardization, metrology, quality management. Standardization determines the ability to normalize and assess sustainability indicators of development, as well as management methods. Metrology provides uniform methods for measuring these indicators. Based on the received information, quality management systems allow making reliable managerial decisions. The use of tools of the economics of quality is possible at almost all stages of socio-economic modelling. The role of elements of the economics of quality, in particular standardization, is especially growing in the development of the digital economy and "smart cities", where a complete unification of the formats for accumulating and transmitting information to all users is required.
\end{abstract}

\section{Introduction}

Modern business conditions are complex and unpredictable. On the one hand, changes are becoming more dynamic, and on the other, the amount of information is sharply increasing. This leads to the fact that when making managerial decisions, specialists are faced with the need to process more and more data, but at the same time, the time for making decisions is constantly reduced. The increasing requirements for quality management complicate this process. Without improving the quality of management, innovations in all sectors of human activity become ineffective. High-quality management largely determines not only the high

\footnotetext{
* Corresponding author: kuzmina2003@bk.ru
} 
sustainability of the development of a country or region, but also the high investment attractiveness of this territory. Indeed, in this case, the investor is guaranteed a return on investment. As a result, a territory with a high quality of management has more and more opportunities to improve the quality of life. For example, today a large flow of investments is being sent to our country. However, according to Professor David Lane, most of the investments go not to where they are most needed today, but to the already successful regions - Yekaterinburg, St. Petersburg and Moscow [1].

\section{Purpose of the study}

It is more and more obvious that today the need for the development of a methodology of social forecasting as a necessary and most important stage in the strategy of social management is growing.

It should be noted that from a practical point of view, the main goal of forecasting is not to give a "ready-made recipe". It is aimed at making the solution development more understandable, helping to identify the basic trends in the study area, the main critical areas, the risks of stepwise changes, the most complex problems, develop options for a management strategy, assess their advantages and disadvantages.

2.1. Five stages of forecasting can be defined:

- the formation of the problem and the choice of forecasting horizon;

- building of a system and identification of key variables;

- data collection and hypothesis;

- the formation of the image of the future using models or scenarios;

- making strategic decisions.

In our opinion, the fourth stage is the most important, since it is at this stage that various scenarios of the development of society are built depending on various initial conditions. At this stage, the final formation of the information base of strategic decisions takes place, which are taken at the next, fifth stage.

Therefore, now the volume of research in the field of modelling the development of society is growing in the whole world. Such modelling is impossible without the use of a mathematical apparatus and supercomputers. Therefore, such modelling is often called mathematical or socio-mathematical.

2.2. In order to show how extensive research is being done in this area, here are a few facts and figures.

For example, in September 2006, a joint project made by eight research canter's in Italy, France, Germany, and Great Britain to develop a large-scale model of the European economy was launched. In its scope and complexity, the model being developed is unique, since it models the behaviour of about 10 million households, about 100 thousand enterprises, and about 100 banks.

In 2012, an unprecedented international and interdisciplinary project to model the technological, social and economic systems of the world - FuturICT - has begun. The project attracted scientists from almost all developed countries. Its implementation period is 10 years, and initial funding is 1 billion euros. The set of models that form the "living planet simulator" through the "observatories" will allow detecting crises and identify solutions to mitigate the consequences. These models will be verified and calibrated using data collected in real time using the "nervous system of the planet".

In China, the National Supercomputer Centre in Guangzhou is developing a simulator for predicting socio-economic dynamics. According to the assurances of the developers, this technological platform of the 21 st century is capable of changing the world. Similar work is being carried out in India at the National Institute of Technology (Durgapur) and at the University of Jadavpur (Calcutta). 
Our country also conducts similar studies, in particular, in the laboratory of experimental economics, which is the flagship for mathematical modelling [2-4].

2.3. Unfortunately, modern models so far can only be applied to solve specific problems of territorial development. The construction of a general socio-mathematical model of a region is currently impossible due to the extreme complexity of the problem. It is enough to indicate that the region as a socio-economic system is clearly anthropogenic in nature, which means that not always predictable actions can take place in such systems.

In addition, other unique properties are inherent in such systems, specifically:

- Emergence, i.e. the presence of such properties that are not inherent in any of the elements that make up the system, taken separately, outside the system. This property arises as a result of the establishment of connections between elements of the system. Therefore, such systems must be investigated and modelled in general.

- The massive nature of economic processes. Consequently, conclusions about economic trends can only be based on mass research.

- Variability. The parameters and structure of the system can actively change under the influence of external factors.

- Inclusion. We cannot observe and investigate economic processes in their pure form, since such systems are open.

Therefore, the created economic forecasts and models of these systems are mainly probabilistic in nature.

\section{Method.}

The way out of this situation is the use of elements of the economics of quality in modelling. Since the purpose and meaning of any development is to improve quality, then development modelling should also take these issues into account. The need to take into account quality in modelling is caused by the multifactorial nature of the quality phenomenon, its permeability and connection with all components of social and economic life.

The results of previous scientific studies have convincingly proved the universality of the tools of the economics of quality. In particular, they may be applicable to ensure the sustainable development of any territory (Fig. 1).

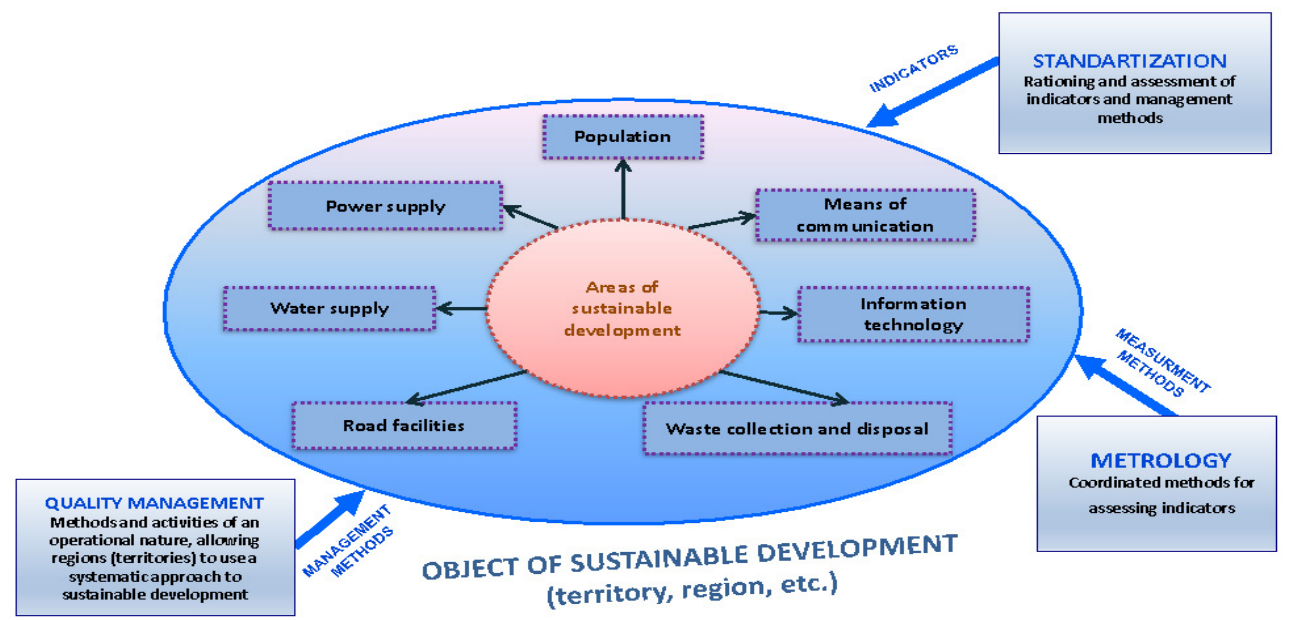

Fig. 1. The impact of elements of the economics of quality on sustainable development 
The object of sustainable development can be a region, territory and any other entity from a small settlement to a single country or an association of states. For each object of sustainable development, several directions can be distinguished in which it is possible to assess the sustainability of its development. Such areas are, for example, energy supply, water supply, road facilities, information technology, waste collection and disposal. Standardization determines the ability to normalize and assess sustainability indicators of development, as well as management methods [5-7]. Metrology provides uniform methods for measuring these indicators. During the measurement, we receive information on the basis of which managerial decisions will be made. How these decisions will be made is the responsibility of quality management. It offers us a systematic approach to management, which allows achieving sustainable development.

Therefore, using the elements of the economics of quality, we can build a model that will more fully meet the requirements set for it. In particular, the use of metrology and standardization will contribute to the universalization of the quantities used in the model and the ability to work with heterogeneous information in accordance with the principles of proportionality. And the use of quality management methods will contribute to the possibility of working with information in conditions of uncertainty, including when concepts are not expressed in terms of universal quantities.

3.1. The analysis showed that the use of tools of the economics of quality is possible at almost all stages of socio-economic modelling.

At the stage of determining goals, objectives and modelling capabilities, elements of the economics of quality contribute to a more complete and adequate definition of modelling goals taking into account the quality factor.

At the stage of analysing a specific problem of territorial development and building a conceptual model of research, elements of the economics of quality are used among the criteria for choosing a development problem. For example, problems of improving the quality of management [8].

At the stage of compiling and structuring the mathematical model, elements of the economics of quality are used to universalize and standardize the indicators used in the model, as well as to select a model management method.

At the stage of analysis and correction of the model, elements of elements of the economics of quality are necessary to conduct analysis of the model in terms of quality and determine the appropriate corrective actions.

At the stage of processing and analysing the modelling results, elements of the economics of quality are necessary for the development of unified methods that allow comparison of various models in order to determine the most effective, as well as develop the most optimal managerial decisions.

At the stage of implementation and support of modelling results, elements of the economics of quality will contribute to a more effective solution to the problems of this stage, as well as a more rapid and complete collection of information on the implementation of modelling results.

3.2. Among the tools of the economics of quality, the special role of standardization should be highlighted. The reasons for this are clear. Indeed, in order to achieve the set goals, it is necessary that all interested parties uniformly understand the meaning and objectives of development. And this cannot be achieved without standardization.

The importance of standardization is even greater in the modern era of the transition to a digital model of economic development. Its visible evidence is the creation of the socalled "smart cities", i.e. cities whose livelihoods are based on the constant use of IT technologies. Due to this, such cities experience significantly less problems - from social to environmental, which cannot but affect the improvement of the quality of life. Today, for example, in Europe, 240 cities can be classified as "smart" ones to one degree or another. 
According to the forecasts of the McKinsey consulting company, in five years, "smart cities" will generate almost two-thirds of world GDP [3].

However, the development of "smart cities" faces many challenges. One of them is information. The lack of a unified system for collecting and analysing data leads to the fact that information comes from a variety of different sources and has many formats, which greatly complicates its analysis.

The need to develop standardization was emphasized during the "Smart City Technology Standards" international conference held on October 11, 2017 in St. Petersburg[9]. According to Mark Fox, a professor at the University of Toronto, today every city has its own idea of how information about its development should look. And you need to make sure that the information analysed is clear to everyone. For example, Toronto does not have a standard for date format. That is, somewhere the year is written at the beginning, and somewhere - at the end. However, misinterpretation, especially by automatic systems, can lead to sad consequences. Variations are not allowed. Qian Heng, director of the Shandong Institute of Standardization, noted that "a smart city is a system of systems: it has no beginning and no end, it is constantly changing through the development of its constituent parts. That is why the availability of relevant standards - the rules for the development of the components of the system, is so important", which contribute to its sustainable development [4].

It is no coincidence that the concept of "smart" St. Petersburg involves the introduction of common standards for the collection and transmission of information, and therefore, the creation of a single information space [5]. Another equally urgent task is the creation of standards in the field of information security. According to experts, today about $15 \%$ of all investments in IT technologies are work in this area of information security.

\section{Conclusions}

In conclusion, it is worth noting that socio-economic modelling contributes to the creation of a highly effective system for managing the development of the territory based on a scientific approach to management, which significantly reduces the risk of making erroneous managerial decisions. After all, the use of elements of the economics of quality can increase the reliability of the information received and used.

Besides, the studies conducted allow us to confidently state that the elements of the economics of quality, in particular standardization, are one of the key factors in ensuring the sustainability of the development of socio-economic systems, since they contribute to the development of fair competition, the widespread introduction of innovations. So, modern standards are effective tools for reducing technical barriers to trade, protecting consumers' interests, protecting the environment and saving all types of resources, which undoubtedly helps to improve the safety of life, health and property of citizens, and has a beneficial effect on increasing the sustainability of development.

\section{References}

1. David Lane. National egoism in the economy // Free economy (2017 ) July-September.

2. Okrepilov V.V., Chudinovskikh I.V. (2018) Economy of the North-West: problems and development prospects. - No. 2 (55)

3. Morunova G., Gorbushina S., Okrepilov V., Kuzmina S, MATEC Web of Conferences, Vol. 239, 08005 (2018),

4. A. Evmenov, S. Kuzmina and V. Vlasova (2018) MATEC Web of Conferences, Vol. 170, 01033 
5. Biais B., Perotti E. C., (2004) Entrepreneurs and new ideas, Centre for Economic Policy Research Discussion Paper Series, no. 3864, available on www.cepr.org

6. Sud, M.; VanSandt, C.V.; Baugous, A. (2009). Journal of Business Ethics. 85: 201216. doi:10.1007/s10551-008-9939-1.

7. Dees J. (1998) The Meaning of Social Entrepreneurship. Stanford: Stanford University Graduate School of Business. URL: http://www.caseatduke.org/documents/dees_SE.pdf

8. McCarthy and Zald (1977) TAJS. 82 (6): 1212-1241. doi: 